\title{
Are Patents Strategic Barriers to Entry?
}

\author{
Corinne Langinier *
}

February 2004

\begin{abstract}
Patent protection restricts entry rather than preventing it. In case of a process innovation, it forces a potential entrant to sufficiently differentiate his production technology. We investigate whether a patentholder threatened by entry can strategically renew her patent. For low demand, the patent renewal is sufficient to deter entry, whereas a high demand attracts competitor, even if there is a patent. On the other hand, the renewal decision can signal information to an uninformed entrant whenever the patentholder is informed. This may act as a barrier to entry. Thus, a patent is renewed more frequently in presence of asymmetric information.
\end{abstract}

Keywords: entry, patent, process innovation

JEL Classification: D82, L12, O34.

*Iowa State University, 260 Heady Hall, Ames, IA 50011-1070. langinier@econ.iastate.edu 


\section{Introduction}

Patents are usually seen as barriers to entry created temporarily by the government. However, in most cases, patent protection restricts entry rather than preventing it. A firm can enter a protected market if his product does not infringe on the current patent: he must respect a minimum novelty requirement. In the case of a process innovation, a potential entrant must reduce his production costs below a threshold imposed by the patent laws. ${ }^{1}$ In a setting where a patentholder is threatened by a potential entrant, we show that if the market is profitable enough, the potential entrant enters with an improvement of the process innovation and thus, both firms are engaged in a duopoly competition. As the patentholder cannot prevent legal entry, she can at least save the renewal cost if she decides not to renew her patent. This is due to the restriction imposed by the government that does not fully protect the patentholder, but rather makes the entrant a stronger competitor. On the contrary, if the profitability is low, the mere constraint imposed by the government prevents entry, and the patentholder is better off if she renews her patent. It is in fact too costly for the entrant to enter the market and the patent is an effective barrier to entry. Thus, depending on the market profitability, a patent can either be a barrier to entry or, on the contrary, make the entrant a stronger competitor. However, when the patentholder is better informed about the demand than her competitor, the patent can be a strategic barrier to entry via the renewal decision. Indeed, the patentholder may try to convey the information that the demand is low, and thus decide to renew her patent strategically. Therefore, when the information is asymmetric, the strategic behavior of the patentholder reduces the likelihood of entry, as renewal occurs more frequently.

The main contribution of our paper is to show that, in the case of a process innovation, the role of the patent as a barrier to entry that may be weakened under symmetric information can be restored in the case of asymmetric information. The decision to renew a patent or not may depend on demand and can thus signal information to an uninformed entrant whenever the patentholder is informed. This may act as a barrier to entry. ${ }^{2}$ There is no clear evidence that firms use renewal decision as a signal. However, it can be of interest to look at the renewal

\footnotetext{
${ }^{1}$ It is sometimes called the "height" of patent protection (van Dijk, 1996).

${ }^{2}$ As does the pricing strategy in the well-known Milgrom Roberts' model (1982).
} 
patent data that have been used in econometric studies to shed light on the value of patents. For instance, French patent data during the 70 s and 80 s, show that about $50 \%$ of patents are dropped out before they reach age 10, and that, the renewal rate for pharmaceutical and chemicals patents is higher than for mechanical or electric patents for French or U.K. origins (Schankerman, 1998). There is thus an industry-specific rate of renewal. ${ }^{3}$ The renewal decision can have several origins. A patentholder may decide to renew her patent to exploit her innovation, to prevent other from using it or to protect herself from being excluded from the market, or it can also be for strategic purposes. She may want to make her uninformed competitor believe that entry is not viable. The patentholder may have a better knowledge of the demand than a potential entrant if, for instance, the product is in a (possibly new) market where there is very little common knowledge about demand. This may partly explain why the renewal rate was higher in pharmaceutical patents than in mechanical patents in the $80 \mathrm{~s}$. Indeed, the demand in pharmaceutical products may have been more uncertain than in mechanical. Pharmaceutical patents are typically granted at an early stage while clinical tests are still in progress, and before being approved by the Food and Drug Administration (FDA). Less than 1 percent of the products examined in the preclinical period make it to human testing (Grabowski, 2002). Furthermore, on average, it takes 14 years from laboratory and animal studies to FDA approval (Viscusi, Vernan and Harrington, 2000). Thus, it results that, early in the life of a patent, the patentholder has a better knowledge about demand as she will be aware of the findings of the clinical tests before her competitor. Even though it is difficult to isolate the signalling part in the renewal decision, we do believe that it plays a non-negligible role as firms use more and more patents as strategic device.

The patent literature has extensively studied the policy implication of different patent requirements (Klemperer, 1990; Gilbert and Shapiro, 1990; Scotchmer and Green, 1990). However, to the best of our knowledge, little attention has been devoted to the use of the patent system by innovators beside the benefit-cost analysis. Horstman, Mac Donald and Slivinsky (1985) and Crampes and Langinier (1998)'s papers are among the few contributions to consider the strategic use of patents. Nevertheless, there exists a significant empirical patent literature that attempts to explain the behavior of innovators as far as patents and R\&D are concerned (for instance

\footnotetext{
${ }^{3}$ It also depends on the origin of the inventor.
} 
Cohen, Nelson and Walsh, 2000). These studies report that innovators claim that patents are the least effective mechanism for protecting invention. However, the recent surge in U.S. patents attests on the contrary that innovators do patent and this is especially true in industries like biotechnology or software industries. A first attempt to explain this recent surge comes from Kortum and Lerner (1999) who claim that this recent jump may be due to a change in management of innovation. Using data from the semi-conductor industry, Hall and Ham-Ziedonis (2001) explain this jump by the "pro-patent" shift in the U.S. legal environment in early 80s and by a strategic management of patent portfolios. Firms make their patenting decision strategically for different purposes: in order to keep or establish their position in a technological domain, to block rivals from patenting related inventions, to expend their portfolio even with lower quality patents for a defensive strategy (Hall and Ham-Ziedonis, 2001) or even to use in negotiation with other firms (Cohen, Levin and Walsh, 2000). Our paper is an attempt at explaining that firms use patents to strategically deter entry of rivals in related areas.

The organization of the paper is the following. In section 2 we set up the model and present the timing of the game. In section 3 we introduce the production and investment subgame. We determine the optimal payoffs for each firm. In section 4, we determine the Perfect Nash equilibrium when the information is perfect. We introduce the imperfect information structure in section 5 and we determine the Perfect Bayesian Equilibrium. Section 6 concludes and presents future extensions.

\section{The Model}

Consider two firms: a patentholder $(H)$, who holds a patent on a process innovation ${ }^{4}$ that she cannot improve upon, ${ }^{5}$ and a potential entrant $(E)$. The patent endows her a protection on different products that are produced using this process. In order to enter, the potential entrant must respect the novelty requirement imposed by the government; he has to sufficiently reduce

\footnotetext{
${ }^{4}$ For instance in the industry of petroleum refining, firms rely heavily on process patents (Cohen, Nelson and Walsh, 2000).

${ }^{5}$ In order to only focus on the strategic signalling of the renewal decision, we rule out the cases where the patentholder may decide to improve on the process innovation and / or to licence it.
} 
his production costs to respect the improvement claims. According to most European patent laws, the patentholder must pay an annual renewal fee to keep her patent in force. ${ }^{6}$ If not, the patent is permanently cancelled, and the potential entrant gains the right to enter freely.

There exists asymmetric information with regards to the value of the demand: only the patentholder knows if the demand is low or high. She must decide whether to renew her patent or not. The potential entrant then observes her decision and tries to infer information. Based on this, he must decide whether to enter the market or not.

While the patent is kept in force, entry is just restricted. The production cost of the new product has to be sufficiently low relative to the costs incurred by the patentholder. The potential entrant has to determine the level of investment he is willing to allocate towards reducing production costs. However, he cannot enter with any level of investment, he must respect the minimum novelty requirement in order to enter the market without infringing on the existing patent.

Neither of the two firms has the same production cost function nor the same "entry" costs. For the patentholder, the "entry" cost is the renewal fee if she pays it. For the potential entrant, entry costs include the installation of the plants and the marketing of the product. Additionally, the entrant must pay to reduce his production costs.

The model is described in a two-period game:

- in the first period, the patentholder decides whether to pay the renewal fee or not. The potential entrant observes this decision and decides whether to enter or not. In the asymmetric information case, the patentholder knows whether demand is high or low, while the entrant only has priors about the States of Nature: $\rho$ denotes the probability that demand is high;

- the second period is an investment and production game where both firms have the same information. If, in the first period, the potential entrant did not enter, the patentholder is a monopolist and chooses her output accordingly. If the potential entrant did enter, it follows that since he now knows the demand, the subgame is a perfect information game

\footnotetext{
${ }^{6}$ Since the early 80s, U.S. law has introduced a renewal fee: the patentholder has to renew her patent at third, seventh and eleventh years.
} 
where first the entrant chooses his investment with respect to cost reduction, and second where both firms compete in quantities. ${ }^{7}$

Using the classical backward induction argument, we first determine the Cournot equilibrium and the investment of the post-entry subgame in section 3. Following this, section 4 characterizes the Nash Perfect equilibrium when the information is perfect. In section 5, when information is imperfect, we characterize the Perfect Bayesian Equilibria of the complete game restricted by the constraint imposed by the government to protect innovations.

\section{Investment and Production Subgame}

We compute the equilibrium quantities sold by firms when both have perfect information about the market profitability. Three alternative market situations are possible:

- if the potential entrant does not enter, the patentholder is a monopolist;

- if the potential entrant enters and the patent is no longer in force, the market is a duopoly.

The level of cost reduction is determined by the entrant without any restriction before firms produce and it is known by both;

- finally, if entry occurs when the patent is still in force, the entrant must respect the novelty requirement in order to not infringe on the patentholder's rights. He is thus forced to invest in cost reduction of at least a minimum amount determined by the government. Knowing this reduction level, both firms then compete in quantities.

\subsection{Choice of Quantities}

The demand for product from each firm $i=H, E$ is represented by:

$$
p_{i}\left(q_{i}, q_{j}\right)=\alpha-q_{i}-\beta q_{j} \text { for } j \neq i
$$

where $\alpha \in\left\{\alpha_{\ell}, \alpha_{h}\right\}$ is an index of market profitability with $\alpha_{h}>\alpha_{\ell}$ and $\beta$ is a differentiation parameter where $\beta \in[0,1]$. The fact that $\beta=0$ implies that the potential entrant has entered

\footnotetext{
${ }^{7}$ We assume that the process innovation is not drastic, and thus if entry occurs both firms compete.
} 
a market different from the patentholder's market, resulting in two juxtaposed monopolies. On the contrary, $\beta=1$ indicates perfect substitutes. The differentiation parameter is perfectly exogenous. ${ }^{8}$

The inverse demand function (1) can be interpreted as the marginal utility of product $i$. The utility function of the representative consumer is

$$
u\left(q_{E}, q_{H}\right)=\alpha\left(q_{E}+q_{H}\right)-\frac{1}{2}\left(q_{E}^{2}+q_{H}^{2}\right)-\beta q_{E} q_{H} .
$$

We assume that both firms do not have the same production cost function. Let $c_{H}$ represent the production cost of the patentholder and $c_{E}$ the production cost of the potential entrant, with $^{9} c_{E}<c_{H}<\alpha_{\ell}$. Furthermore, we assume that $\alpha_{\ell}-c_{H}$ is big enough to insure the existence of interior solutions.

We first determine the socially optimal quantities. These quantities are determined by the solution of

$$
\max _{q_{E}, q_{H}} u\left(q_{E}, q_{H}\right)-c_{E} q_{E}-c_{H} q_{H}
$$

and their values are

$$
q_{i}^{0}=\frac{m_{i}-\beta m_{j}}{1-\beta^{2}} \quad i \neq j \text { and } i, j=E, H,
$$

where $m_{i}=\alpha-c_{i}$ represents firm $i$ 's size of demand. ${ }^{10}$ The maximal social welfare is thus

$$
V\left(q_{E}^{0}, q_{H}^{0}\right)=\frac{m_{E} m_{H}}{1+\beta}+\frac{\left(m_{E}-m_{H}\right)^{2}}{2\left(1-\beta^{2}\right)} .
$$

Second, we consider the case of a private monopoly, which corresponds to the situation where the potential entrant decides to not enter, and thus the patentholder is in a monopolistic situation. The problem of the patentholder is then

$$
\max _{q_{H}}\left(\alpha-q_{H}-c_{H}\right) q_{H}
$$

\footnotetext{
${ }^{8}$ We study the case of an endogenous determination of the differentiation parameter in a model in which the entrant has to respect a differentiated constraint in Crampes and Langinier (1998). The structure of the model is similar except that here the constraint is on the cost of production and not on the differentiation parameter. The results are highly dependent on the chosen constraint.

${ }^{9}$ This inequality makes sense if we consider that the potential entrant has already done a reduction of cost after the introduction of the patent due to spillover effects.

${ }^{10}$ To insure these values to be positive, we assume that $\beta<\frac{m_{H}}{m_{E}}$.
} 
So, she produces $q_{H}^{M}=m_{H} / 2$ and her equilibrium profit is

$$
\Pi_{H}^{M}=\frac{m_{H}^{2}}{4} .
$$

As a third case, consider the duopoly structure with differentiated demands (1). Recall that there is perfect information about $\alpha$. Firm $i=E, H$ solves

$$
\max _{q_{i}}\left(\alpha-q_{i}-\beta q_{j}^{*}-c_{i}\right) q_{i} \quad j \neq i .
$$

It is straightforward to calculate the equilibrium quantities

$$
q_{i}^{*}=\frac{2 m_{i}-\beta m_{j}}{4-\beta^{2}} \text { for } j \neq i, j, i=E, H
$$

and the equilibrium profits are

$$
\Pi_{i}^{*}=\left(\frac{2 m_{i}-\beta m_{j}}{4-\beta^{2}}\right)^{2} \text { where } i \neq j \text { and } i, j=H, E .
$$

We then determine the level of investment that is required of the entrant in order to reduce his production costs. Recall that these payoffs depend also on the fact that the demand can be high $\left(\alpha_{h}\right)$ or low $\left(\alpha_{\ell}\right)$. We will thus denote $\Pi_{i}^{h}$ (respectively $\Pi_{i}^{l}$ ) the payoff of $i=H, E$ in a market with high demand (respectively low demand).

\subsection{Choice of Investments}

We now assume that the potential entrant can modify the production cost by his investment $I$. This investment level is chosen after entry has occurred. We denote $m_{E}(I)=\alpha-c_{E}(I)$ where $c_{E}(I)$ is such that $c_{E}^{\prime}(I)<0, c_{E}^{\prime \prime}(I)>0$ and $-c_{E}^{\prime \prime}(I)\left[2\left(\alpha-c_{E}(I)\right)-\beta\left(\alpha-c_{H}\right)\right]+2\left(c_{E}^{\prime}(I)\right)^{2}<0 .{ }^{11}$ Thus $m_{E}^{\prime}(I)>0$ and $m_{E}^{\prime \prime}(I)<0$. The payoffs are now function of the investment of the entrant, $\Pi_{i}^{h}(I)$ or $\Pi_{i}^{l}(I)$ for $i=H, E$. For the time being we drop the superscript $h$ and $l$ to simplify the notation.

When the patentholder has not paid the renewal fee, the entrant is free to choose $I$ to maximize his net profit:

$$
\max _{I}\left(\frac{2 m_{E}(I)-\beta m_{H}}{4-\beta^{2}}\right)^{2}-I-a_{E},
$$

\footnotetext{
${ }^{11}$ For instance, this condition is satisfied for an exponential cost function $c_{E}(I)=c e^{-I}$ and $\beta<2 \frac{\alpha-2 c_{E}(I)}{\alpha-c_{H}}$.
} 
where $a_{E}$ is a fixed entry cost that the entrant has to pay.

The optimal investment $I^{*}$ is the solution of

$$
\frac{4 m_{E}^{\prime}(I)\left[2 m_{E}(I)-\beta m_{H}\right]}{\left(4-\beta^{2}\right)^{2}}-1=0 .
$$

Nevertheless, the potential entrant must respect an entry constraint and cannot freely choose his level of production cost as the government forces him to incur production costs that respect a constrained level.

The public authority program is the following:

$$
\max _{I} \frac{m_{E}(I) m_{H}}{1+\beta}+\frac{\left(m_{E}(I)-m_{H}\right)^{2}}{2\left(1-\beta^{2}\right)}-I-a_{E}-a_{H},
$$

where $a_{H}$ is the renewal fee paid by the patentholder to keep her patent in force.

The optimal investment $I^{o}$ is the solution of

$$
m_{E}^{\prime}(I)\left[\frac{m_{H}}{1+\beta}+\frac{m_{E}(I)-m_{H}}{1-\beta^{2}}\right]-1=0 .
$$

The comparison of the levels of investment leads to the following result.

Proposition 1 : For a given level of differentiation $\beta$ small enough and if there exist $I^{*}$ and $I^{o}$ that belong to $\left[0, m_{E}^{-1}\left(\frac{m_{H}}{\beta}\right)\right]$, then $I^{o}>I^{*}$.

Proofs are given in the appendix.

The entrant underinvests in cost reduction relative to the social optimum. This result is similar to one of the findings of Bester and Petrakis (1993) ${ }^{12}$ in a model where they investigate whether the incentive for cost reduction depend upon the degree of production substitution. Related, it is also consistent with Eswaran and Gallini (1996)'s findings in a model where they mix product and process innovation.

Therefore the entrant has less of an incentive to introduce the new product as he cannot appropriate all the social surplus. The level of investment imposed by the government is always

\footnotetext{
${ }^{12}$ In their study this is true for large reduction of cost which is always satisfied here. Indeed, if $\Delta$ is the cost reduction of the challenger, the reduction is large if $\Delta>2\left(c_{E}-c_{H}\right)$. This last inequality is always satisfied since $c_{E}-c_{H}<0$.
} 
greater than the level of investment freely chosen by the entrant. Thus, the latter is always constrained to invest in a reduction of cost.

The condition on $\beta$ imposes a certain degree of differentiation. If the product is differentiated enough, the potential entrant does not want to bear an important cost to reduce the production costs. Nevertheless, the differentiation is not enough from the mere social viewpoint.

In order to induce innovators to undertake $R \& D$ projects, patentholders need to have sufficient protection. This protection is such that the entrant must sufficiently reduce the marginal cost of production and thus he can enter the market only if he has a product that satisfied the legal novelty requirement.

We now specify a condition for the legal novelty requirement: ${ }^{13}$

$$
I \text { must be such that } \xi \leq c_{H}-c_{E}(I) \Leftrightarrow c_{E}(I) \leq c_{H}-\xi \text {, }
$$

where $\xi$ is the novelty requirement that must be satisfied for the entrant to produce his variant product. The novelty requirement is a reduction in the marginal cost required of the subsequent entrant's process relative to the patentholder. We consider that $\xi$ and $c_{H}$ are exogenous.

This condition determines the minimum requirement that must be respected; from this, the potential entrant can respect the minimum size of the innovation required. He can only enter the market with an improvement that can decrease the cost of production under a cut-off value, $c_{H}-\xi$. Thus, there exists $I^{c}$ such that $I^{c}=c_{E}^{-1}\left(c_{H}-\xi\right)$. If the potential entrant wishes to enter the market, he must spend at least $I^{c}$ in order to reduce his marginal cost of production.

The new regulator program is

$$
\left\{\begin{array}{l}
\max _{I} \frac{\left(\alpha-c_{E}(I)\right)\left(\alpha-c_{H}\right)}{1+\beta}+\frac{\left(c_{H}-c_{E}(I)\right)^{2}}{2\left(1-\beta^{2}\right)}-I \\
\text { s.t. } I \geq I^{c}
\end{array}\right.
$$

The social optimum $I^{S O}$ that takes into account the constraint is then $I^{S O}=\max \left\{I^{o}, I^{c}\right\}$. A comparison between the different levels of investment leads to the following proposition.

Proposition 2 : The social optimal level of investment is such that $I^{S O}>I^{*}$.

\footnotetext{
${ }^{13}$ We use the same definition as in Eswaran and Gallini (1996).
} 
The entrant has to reduce his production costs more than he would be willing to do. This restriction does not protect the patentholder, it makes the entrant a stronger competitor. Indeed, the extra investment undertaken by the entrant to reduce his cost of production reduces the patentholder's payoff, i.e., $d \Pi_{H}^{*}(I) / d I<0$. The improvement of the total social welfare does not increase the patentholder's payoff.

This kind of policy does not protect the patentholder even if the social welfare is enough to justify entry. Thus, the total welfare increases while the patentholder's payoff decreases. This policy seems to be in contradiction with the patent system which aim is to protect the first innovator. This gives rise to the issue of how payoffs are distributed from the potential entrant to the patentholder. This problem has been pointed out several times by Scotchmer (Scotchmer, 1996; Green and Scotchmer, 1995). Conceivably to avoid this result, the potential entrant should provide a transfer to the patentholder in order to recoup the $\mathrm{R} \& \mathrm{D}$ investment not yet recovered. However we do not address this problem here. Our analysis is limited to the natural barriers to entry, namely the entry cost for the potential entrant under certain circumstances.

The condition on $\beta$ that insures positive quantities can be rewritten as

$$
\beta<\min \left\{\frac{m_{H}}{m_{E}\left(I^{o}\right)}, \frac{m_{H}}{m_{E}\left(I^{c}\right)}\right\} .
$$

This is also a condition on the levels of optimal investment, as they must belong to the interval $\left[0, m_{E}^{-1}\left(\frac{m_{H}}{\beta}\right)\right]$ in order to insure that positive quantities are produced.

We now turn to the first stage of the game, the decision stage. As a benchmark case, we consider the case in which the information is perfect: each firm knows perfectly whether the demand is low or high. Then, we consider the case in which only the patentholder knows the value of demand and decides to behave strategically in order not to reveal it.

\section{Perfect Information}

Consider the case in which both firms have the same information concerning the demand. Depending on its value (high or low), the patentholder and the potential entrant will respectively decide whether to renew or not and whether to enter or not the market. The patentholder has to pay a renewal fee $\left(a_{H}\right)$ in order to keep her patent in force while the potential entrant 
has to pay an entry cost. This latter cost has two components: a real entry cost $\left(a_{E}\right)$ and the investment needed to reduce the production costs $(I)$. We assume that $a_{H}$ and $a_{E}$ are given while $I$ is determined endogenously by the potential entrant. We assume that

$$
\begin{gathered}
a_{H}<\Pi_{H}^{l}(0)-\Pi_{H}^{l}\left(I_{l}^{*}\right), \\
\Pi_{E}^{l}\left(I_{l}^{o}\right)-I_{l}^{o} \leq a_{E}<\Pi_{E}^{l}\left(I_{l}^{*}\right)-I_{l}^{*} .
\end{gathered}
$$

The assumption (9) means that the patentholder's net monopoly payoff is always bigger than the duopoly payoff. This implies that the renewal cost is not too high, which is fairly consistent with the actual renewal fees scheme paid by patentholders. ${ }^{14}$ The assumption (10) insures that the entry cost, representing the acquisition of machines, know-how needed to improve the original innovation, is not too high. It is in fact such that entry is not viable if the innovation process is patented in case of low demand. On the other hand, if the demand is high, the entry cost cannot prevent entry.

In the case of perfect information, we can state the following proposition:

Proposition 3 : If (8), (9) and (10) are satisfied, there exists a Perfect Nash Equilibrium such that

1. the patentholder decides to not renew her patent in the case of high demand, and to renew it in the case of low demand;

2. the potential entrant decides to enter if he observes a non-renewal, and to not enter otherwise.

If the demand is low, the barrier to entry is just the entry cost. If the patent has been renewed, the potential entrant will not enter: the entry cost plus the investment that he has to incur in order to reduce the production costs are too high. The market is thus too narrow for two firms and the patentholder can then deter entry if she decides to renew her patent. In fact, the choice of renewing the patent leads to two opposite effects on the profit of the potential entrant. A direct effect has a negative impact on his profit because he is forced to invest in

\footnotetext{
${ }^{14}$ In the U.S. the 2003 maintenance fees are $\$ 890$ in year $3, \$ 2050$ in year 7 and $\$ 3150$ in year 11.
} 
cost reduction, whereas a strategic effect is positive because the renewal decision decreases the quantity offered by the patentholder. Overall the direct effect is bigger than the strategic effect.

On the contrary, if the demand is high, even if the patent has been kept in force, the entry cost is not large enough to deter entry. In this case, the market is large enough for two firms even though one firm holds a patent and the other firm legally enters. Thus, the patentholder who cannot deter entry, can only accommodate it and save both the renewal cost and the reduction in payoff associated with a higher investment undertaken by the entrant. The renewal decision has also two effects (direct and strategic effects) on the profit of the patentholder, but both effects are negative and thus push her to abandon her patent.

\section{Imperfect Information}

We now consider the case in which the potential entrant has imperfect information concerning the demand. The concept used is the concept of Perfect Bayesian Equilibrium. We find different equilibria in pure and mixed strategies. First, the patentholder will never choose a strategy that reveals the value of the demand (i.e., there is no separating equilibrium in pure strategies). With respect to pure strategies, we find a unique Pooling equilibrium that is supported by beliefs that satisfied Cho and Kreps' (1987) Intuitive Criterion. In mixed strategies, we find a semi-separating equilibrium for certain values of the beliefs of the potential entrant. We first consider the equilibria in pure strategies followed by those in mixed strategies.

\subsection{Pooling Equilibrium}

The patentholder can decide to choose the same strategy regardless of the value of the demand. In this case the potential entrant cannot learn any information from the observation of the patentholder's decision and his prior beliefs are equal to his posterior beliefs.

The only reasonable Pooling equilibrium is the following: ${ }^{15}$

Proposition 4 : If (8), (9) and (10) are satisfied and if the Perfect Bayesian Equilibrium outcome is supported by beliefs satisfying Cho and Kreps' (1987) Intuitive Criterion, for $\rho<\rho^{*}$,

\footnotetext{
${ }^{15}$ The proofs of propositions 4 and 5 are available from the author on request.
} 
there exists a unique Pooling equilibrium in pure strategies such that

1. the patentholder decides to renew her patent whatever the value of the demand;

2. the potential entrant does not enter after observing a renewal.

In this case, if the potential entrant has low prior beliefs, and consequently low posterior beliefs, the patentholder decides to renew her patent and the potential entrant will decide not to enter the market. The renewal decision prevents entry because it does not give any information to the potential entrant, who has already low prior beliefs.

\subsection{Semi-Separating Equilibrium}

The patentholder can decide to choose the same action for one value of the demand and then to choose a random action for the other value of the demand. The patentholder thus does not completely reveal the value of the demand by the chosen action. This equilibrium is a semiseparating equilibrium in mixed strategies and we summarize it in the following proposition:

Proposition 5 : If (8), (9) and (10) are satisfied, and for $\rho \geq \rho^{*}$, there exists a semi-separating equilibrium in mixed strategies such that

1. the patentholder decides to renew her patent for low demand and randomize her decision for high demand;

2. the potential entrant decides to enter after observing a non-renewal, and to randomize his decision after observing a renewal.

The patentholder decides to always renew her patent for low demand, and to randomize her decision otherwise. The observation of the non-renewal implies that the demand is high, and thus the potential entrant enters the market. On the other hand, the observation of the renewal does not bring any information. It just allows the entrant to update his prior beliefs; his posterior beliefs assign more weight to the low demand state and he also randomizes his entry decision. The likelihood of entry is thus reduced. 
The patentholder makes her behavior unpredictable and thus forces the potential entrant to behave randomly. Thus, overall, the entrant will enter less often than in the symmetric case. That is why the patent can be seen as a strategic barrier to entry.

\section{Conclusion}

A patent is not always an effective barrier to entry as it only restricts entry rather than preventing it. This is especially true in the case of process innovation where the entry constraint imposed by public authorities makes the entrant a stronger competitor if he can respect the novelty requirement. In our setting, it appears to be the case when the demand is high. Conversely, when the demand is low, the patent is a barrier to entry as long as the patentholder renews her patent. Our main contribution is to show that, in case of asymmetric information about the demand size, the patentholder can renew strategically her patent in order to pretend that the demand is low and to create a barrier to entry. Thus, the asymmetric information on the demand has an influence on the renewal strategy of the patentholder in the case of process innovation.

This outcome is highly dependent on some assumptions. First, we assume that the patentholder cannot reduce her own production costs. If we assume that both firms are engaged in a race, the outcome will be different. Second, we abstract from time constraint. Indeed, we do not take into account that is can take time for the entrant to invest in a reduction of production costs. Nevertheless the outcome will still be consistent with ours if we relax this assumption. Related, we assume that the entrant always succeed in finding a better technology. However, the entrant could either fail (and then it is possible to have a probability of finding), or the entrant could end up with a different and not necessarily better technology. Finally, we assume that the patentholder is threatened by just one potential entrant. If we let several potential entrants threaten the patentholder, the results will be different.

Our focus is on process innovation, which represents one-fourth of the investment devoted to research. It will be interesting to consider a mix between process and product innovation as in Eswaran and Gallini (1996) and to see how the level of differentiation imposed on the entrant will affect the reduction of production costs and vice-versa. This extension is in our future agenda of research. 


\section{APPENDIX}

\section{Proof of Proposition 1}

The comparison of the first order conditions is the following. We first evaluate the first order

condition (7) at $I^{*}$. Thus, from (6) we have $m_{E}^{\prime}\left(I^{*}\right)=\frac{\left(4-\beta^{2}\right)^{2}}{4\left[2 m_{E}\left(I^{*}\right)-\beta m_{H}\right]}$ which we introduce in (7). In doing so, we obtain

$$
\frac{1}{\left(1-\beta^{2}\right)\left(4-\beta^{2}\right)^{2}}\left[m_{H}\left(-\beta^{5}+4 \beta^{3}-12 \beta\right)+m_{E}\left(I^{*}\right)\left(\beta^{4}+8\right)\right]
$$

The sign of the expression in brackets will determine the sign of this expression. Denote $A=$ $-\left(\beta^{5}-4 \beta^{3}+12 \beta\right)$ and $B=\beta^{4}+8$. Recall that $m_{E}(I)>m_{H}$ for any $I$ and thus $m_{E}(I)>\frac{A}{B} m_{H}$

if $\frac{A}{B}<1$. Let's check that $\frac{A}{B}<1$. This expression is equivalent to $\beta^{5}-4 \beta^{3}+12 \beta-\beta^{4}-8<0$ that we can factorize $(\beta-1)(\beta-2)\left(\beta^{3}+2 \beta^{2}-4\right)<0$. It is obvious that the last inequality is always satisfied, so $\frac{A}{B}<1$, and then that the condition (11) is strictly positive. So, the first order condition that gives $I^{o}$ is positive, and thus $I^{*}<I^{o}$. Furthermore to insure the existence of positive quantities we must assume that $\beta<\frac{m_{H}}{m_{E}(I)}$. This implies that $\beta$ must be small enough. But this is not enough to insure that the investments will lead to positive quantities. We need to make sure that the investment levels belong to the interval $\left[0, m_{E}^{-1}\left(\frac{m_{H}}{\beta}\right)\right]$.

\section{Proof of Proposition 2}

If $I^{o}>I^{c}$ then $I^{S O}=I^{o}>I^{*}$; if $I^{o}<I^{c}$ then $I^{S O}=I^{c}>I^{o}>I^{*}$.

\section{Proof of Proposition 3}

By backward induction we first determine the optimal solution of the potential entrant, and then determine the optimal decision of the patentholder. When $\alpha=\alpha_{h}$, the potential entrant will always choose to enter due to assumption (10). Indeed if $a_{E}<\Pi_{E}^{l}\left(I_{l}^{*}\right)-I_{l}^{*}$ then $a_{E}<\Pi_{E}^{h}\left(I_{h}^{*}\right)-I_{h}^{*}$. Thus, with assumption (9) the patentholder will choose not to renew her patent. When $\alpha=\alpha_{l}$, the potential entrant will enter the market if the patentholder does not renew her patent because from assumption $(10) a_{E}<\Pi_{E}^{l}\left(I_{l}^{*}\right)-I_{l}^{*}$. On the contrary, the potential entrant will not enter if the patentholder decides to renew her patent. The patentholder will decide to renew her patent because $a_{H}<\Pi_{H}^{l}(0)-\Pi_{H}^{l}\left(I_{l}^{*}\right)$. 


\section{References}

[1] Bester, H. and E. Petrakis. "The Incentives for Cost Reduction in a Differentiated Industry," International Journal of Industrial Organization, 11:519-534 (1993).

[2] Cho, I. and D. M. Kreps. "Signalling Games and Stable Equilibria," Quarterly Journal of Economics, 102:179-221 (1987).

[3] Cohen W., R. Nelson and J. Walsh. "Protecting their Intellectual Assets: Appropriability Conditions and Why US Manufacturing Firms Patent (or Not)," NBER Working Paper, $W 7552(2000)$.

[4] Crampes, C. and C. Langinier. "Information Disclosure in the Renewal of Patents," Les Annales d'Economie et Statistique, 49/50:266-288 (1998).

[5] Eswaran, M. and N. Gallini. "Patent Policy and the Direction of Technological Change," RAND Journal of Economics, 27:722-746 (1996).

[6] Gilbert, R. and C. Shapiro. "Optimal Patent Length and Breadth," RAND Journal of Economics, 21:106-112 (1990).

[7] Grabowski, H. "Patents, Innovation and Access to New Pharmaceuticals," working paper (2002).

[8] Green, J.R and S. Scotchmer. "On the Division of Profit in Sequential Innovation," RAND Journal of Economics, 26(1):20-33 (1995).

[9] Hall, B. and R. M. Ham Ziedonis. "The Patent Paradox Revisited: Determinants of Patenting in the US Semiconductor Industry, 1979-95," RAND Journal of Economics, 32, No. $1: 101-128$ (2001).

[10] Horstmann I., G.M. MacDonald and A. Slivinski. "Patents as Information Transfer Mechanisms: To Patent or (Maybe) Not to Patent," Journal of Political Economy, 93:837-858 (1985). 
[11] Klemperer, P. "How Broad Should the Scope of Patent Protection Be?," RAND Journal of Economics, 21:113-130 (1990).

[12] Kortum, S. and J. Lerner. "What is Behind the Recent Surge in Patenting?," Research Policy, 28:1-28 (1999).

[13] Milgrom, P. and J. Roberts. "Limit Pricing and Entry under Incomplete Information: An Equilibrium Analysis," econometrica, 50:443-460 (1982).

[14] O’Donoghue, T. "A Patentability Requirement for Sequential Innovation," RAND Journal of Economics, 29:654-679 (1998).

[15] Schankerman, M. "How Valuable is Patent Protection: Estimates by Technological Field," RAND Journal of Economics, 29:77-107 (1998).

[16] Scotchmer, S. "Protecting Early Innovators: Should Second Generation Product Be Patentable?," RAND Journal of Economics, 27:322-331 (1996).

[17] Scotchmer, S. and J. Green. "Novelty and Disclosure in Patent Law," RAND Journal of Economics, 21:131-146 (1990).

[18] Van Dijk, T. "Patent Height and Competition in Product Improvements," Journal of Industrial Economics, 44:151-167 (1996).

[19] Viscusi W., J. Vernon and J. Harrington. Economics of Regulation and Antitrust. Cambridge, MA 02142: The MIT press, 2000. 